\title{
Waiting for the sun - can temporal flexibility in BEV charging avoid carbon emissions?
}

\author{
Julian Huber ${ }^{1 *}$ and Christof Weinhardt ${ }^{2}$ \\ From The 7th DACH+ Conference on Energy Informatics \\ Oldenburg, Germany. 11-12 October 2018
}

*Correspondence:

julian.huber@fzi.de

${ }^{1}$ FZI Research Center for

Information Technology,

Haid-und-Neu-Str. 10-14, 76131

Karlsruhe, Germany

Full list of author information is

available at the end of the article

\begin{abstract}
Battery Electric Vehicles (BEVs) are claimed to foster climate-neutral energy and transportation systems. However, the use of the BEVs shifts emissions only geographically. In addition, the charging of BEVs can lead to new problems, such as congestions in the electricity grid. Smart charging algorithms can avoid some of these problems. To do this, however, the BEV user must actively decide to make her temporal flexibility available. Feedback on possible $\mathrm{CO}_{2}$ savings could be a nudge that encourages $\mathrm{BEV}$ users to provide more temporal flexibility. We compare different charging events and algorithms to determine the savings in $\mathrm{CO}_{2}$ emissions of $\mathrm{BEV}$ charging. We find that temporal flexibility can on average save of $\mathrm{CO}_{2}$ emissions in the single-digit percentage range in Germany. The results can be used to implement a feedback nudge in smart charging systems to test its effectiveness on the provision of temporal charging flexibility of BEV users.
\end{abstract}

Keywords: Battery Electric Vehicles, Smart charging, Carbon emission, Digital nudging

\section{Background}

Road transport accounts for $20 \%$ of global $\mathrm{CO}_{2}$ emissions. The switch to locally emissionfree Battery Electric Vehicles (BEVs) is supposed to support the transition to a climateneutral energy system (Santos 2017). However, higher numbers of BEVs also result in new challenges. On the one hand, uncontrolled charging can stress the electricity grids (Clement-Nyns et al. 2010). On the other hand, in many countries electricity is still mainly generated from fossil fuels. In this case a change towards BEVs only shifts the location where the $\mathrm{CO}_{2}$ is emitted. (However, other pollutants might be better retained in central generation plants.) One solution could be the use of electricity with certificates of $\mathrm{CO}_{2}$ neutral origin for the charging process. These certificates ensure an on-balance-sheet compensation between generated and consumed energy. This means that for each energy unit sold, the energy supplier must procure the same amount from renewable sources. However, this on-balance-sheet compensation is often calculated over long time periods. This does not guarantee that the electricity received at any given time is covered by renewable generation. Smart charging is an alternative to this. It controls the BEV's charging

(c) The Author(s). 2018 Open Access This article is distributed under the terms of the Creative Commons Attribution 4.0 International License (http://creativecommons.org/licenses/by/4.0/), which permits unrestricted use, distribution, and reproduction in any medium, provided you give appropriate credit to the original author(s) and the source, provide a link to the Creative Commons license, and indicate if changes were made. 
process according to the BEV user's preferences. For example, she can use a smart charging system to increase the share of renewable energies in the system (Schuller et al. 2015) or to pay a lower price (Salah and Flath 2016).

However, smart charging only works if the BEV user is fully integrated into the process. The algorithms of smart charging systems require the user's specific charging flexibility to schedule an optimal charging process. A BEV user can, for example, provide temporal charging flexibility if she is willing to postpone charging of the BEV in time. Since smart charging systems usually cannot decide how flexible the user is (when and how far she wants to drive), the user must manually enter her charging flexibility into the smart charging system.

In principle, many BEV users are willing to use smart charging. Will and Schuller (2016) found that BEV users are particularly willing to provide charging flexibility when it is used to integrate renewable energies. However, in comparable situations, researchers often observe a difference between reported intent and actual action: Schultz et al. (2007) show, for example, that the number of actually contracted green electricity tariffs is well below the reported acceptance. Such discrepancies between intention and actual behavior can often be explained by heuristics and biases (Tversky and Kahneman 1974). The understanding of such effects and the underlying processes can be used to deliberately design the decision environment to overcome this biases. Thaler and Sunstein (2008) call this process choice architecture where so-called nudges steer the users towards better decisions. If the decision environment is an information system (e.g., a smart charging system) the choice architect can employ digital nudging by adapting its design features (Weinmann et al. 2016).

An important tool of choice architecture is the framing of information and immediate feedback on the users actions (Münscher et al. 2016). For example, Feedback on energy and $\mathrm{CO}_{2}$ savings can encourage households to save energy (Grønhøj and Thøgersen 2011; Asensio and Delmas 2016; Schultz et al. 2007).

In analogy, we suggest that feedback about $\mathrm{CO}_{2}$ saving potentials of charging flexibility can stimulate $\mathrm{BEV}$ users to provide more charging flexibility and avoid $\mathrm{CO}_{2}$ emissions. As a basis for further investigations we explore the potential of $\mathrm{CO}_{2}$ reduction by temporal charging flexibility in the Germany electricity market. We answer the following research question: What are the $\mathrm{CO}_{2}$ saving potentials for shifted BEV charging in Germany? To this end, we compare immediate charging (without providing flexibility) with two charging algorithms (cost and $\mathrm{CO}_{2}$ optimized charging). We base our analysis on the generation and electricity market data for Germany 2017.

The remainder of the paper is structured as follows. First, we explain why feedback about $\mathrm{CO}_{2}$ savings potentials is a promising candidate for a digital nudge to increase the charging flexibility of BEV users. Subsequently, the data basis and the method for estimating the $\mathrm{CO}_{2}$ saving potential are presented. The paper concludes with a presentation and discussion of the results and an outlook on the further use of the results.

\section{Related work}

Based on the ideas of choice architecture (Thaler and Sunstein 2008), Weinmann et al. (2016) propose a framework for the development of digital nudges. The five steps of the framework include the definition of digital context and goals, understanding of the 
users decision process, selection and implementation of the nudge, and last, testing in an experimental setting. In the following we follow first four steps of the digital nudging framework to implement a feedback nudge on $\mathrm{CO}_{2}$ emissions. The main focus is on estimating the $\mathrm{CO}_{2}$ saving potential of postponed charging. This is the basis for the implementation of the nudge (i.e., feedback on avoided $\mathrm{CO}_{2}$ emissions depending on the offered temporal charging flexibility) and allows to test the effectivity of the nudge in an experimental setting.

\section{Digital context and goals}

Our goal is to design an information system for smart charging that provides direct feedback on $\mathrm{CO}_{2}$ emissions avoided through a smart charging algorithm. This means that the user can plug her BEV into a charging station and enter her charging flexibility via an app or via an interface of the charging station. To simplify matters, we only consider temporal charging flexibility. This means that the charging flexibility is determined by the time at which the user wants her BEV to be charged to full capacity. Providing energy flexibility as defined in Ludwig et al. (2017) by reducing the amount of energy that is required at the end of the charging process is not considered.

There are different possibilities, when the user can enter her temporal flexibility. On the one hand, she can set a default for her temporal flexibility. This could happen when logging into a charging system for the first time. Alternatively, systems could provide an affordance for entering temporal flexibility at the beginning of each charging process. In both cases, information about the $\mathrm{CO}_{2}$ savings could nudge $\mathrm{BEV}$ users towards providing more temporal flexibility.

\section{Understand decision process}

Various factors determine the acceptance of the smart charging. In a survey, Will and Schuller (2016) examined which factors supported the acceptance of smart charging. $\mathrm{BEV}$ users are more likely to accept smart charging if it does not restrict their mobility behaviour, contributes to grid stability, or fosters the integration of renewable energies. Monetary incentives were not considered important by the BEV users in the survey. Following these results, there are two non-monetary incentives that could lead users to provide more temporal flexibility. To show users the load status of their distribution grid, the gird must be equipped with intelligent measurement technology. In addition, network bottlenecks in the distribution network are a local problem that must be determined individually for each user. In contrary, $\mathrm{CO}_{2}$ emissions can be compared globally and are better understood by BEV users, as there is a medium-high self-reported understanding global warming in the throughout population (McCright and Dunlap 2011). It can therefore be assumed that $\mathrm{CO}_{2}$ emissions play a driving role in the decision on providing flexibility. However, most electricity consumers in general and BEV users in particular do not receive any feedback as to when electricity should be used in order to reduce $\mathrm{CO}_{2}$ emissions.

Various works show an effect of feedback on the energy conservation in households. Grønhøj and Thøgersen (2011) find that visible and salient feedback on displays leads to energy savings of $8.1 \%$. In addition, Asensio and Delmas (2016) show that feedback about energy consumption is particularly effective when it is framed as a health issue. In contrary, if the feedback only mentions the cost savings, the energy savings are lower 
and only made over a short period of time. Likewise, normative feedback can help households save energy. Schultz et al. (2007) show at influence of social norms by communicating information about their income and energy consumption of their neighbors to households.

Direct feedback is also successfully used in vehicles (BEV and car with internal combustion engine) to encourage drivers to adopt a more efficient and thus environmentally friendly driving style (Magana and Munoz-Organero 2011).

\section{Select nudge}

The previous findings let us assume that feedback on $\mathrm{CO}_{2}$ savings could also be an important driver to provide charging flexibility. Feedback mechanisms have been successfully used both in household and in vehicles to encourage users to behave in an environmentally friendly manner.

Nudges or design elements can be divided into three categories (Münscher et al. 2016): First, the decision information can be changed (for example, if the information is put in a different light by a framing energy conservation as an health issue). Second, the structure of the decision can be changed (for example, if the order of dishes on a menu is changed). Third, the decision can be supported by reminder or similar tools.

An information system that gives feedback about the $\mathrm{CO}_{2}$ saving potentials for a certain charging flexibility can be described within this taxonomy as follows: The information system changes the decision information by translating the information. By communicating the $\mathrm{CO}_{2}$ savings it reframes the problem to an environmental context (besides, money can be saved through load shifting.) Furthermore, it changes the decision information by making the impact of the own behavior (i.e., providing flexibility) visible in the decision environment (i.e., the potential $\mathrm{CO}_{2}$ savings).

\section{Implement nudge}

The nudge is to be implemented as follows: The BEV user enters her charging flexibility into the charging system and receives feedback on the possible $\mathrm{CO}_{2}$ saving potentials with the given amount of temporal flexibility. For this, an algorithm must predict the $\mathrm{CO}_{2}$ saving potentials during the charging process and report them back to the user. In this paper, we limit the algorithm to a post-hoc analysis of historical data.

Similar algorithms for smart charging have already been implemented elsewhere. Gottwalt et al. (2013) develop a mixed-integer optimization program to coordinate BEV charging to maximize the use of renewable energy in a generation portfolio. However, they do not consider greenhouse gas emissions and only consider local generation. Sortomme and El-Sharkawi (2011) optimize the charging to ensure grid stability. However, the authors are not aware of any algorithms that focus on decision support and incentives for the BEV users.

\section{Data}

To provide the user with a first feedback on the $\mathrm{CO}_{2}$ savings potential with various charging algorithms, we use historical data. In this analysis, we use the publicly available data of German power generation (15 min resolution) and the wholesale prices (60 min resolution) from 2017 (SMARD). 


\section{Generation and price data}

The structure of German power generation is published in a 15-min resolution. It differentiates different types of generation units mentioned in Table 1. Imports and exports are not taken into account.

In Germany, time-of-use tariffs are still not widespread. For this reason, we used wholesale market prices for the evaluation. They are significantly lower than the actual electricity price for BEV users, as they do not include taxes or levies, such as network charges, which account for a large part of the electricity price for end users. However, the prices are used to illustrate the temporal differences in electricity prices. Since taxes and charges are not time-dependent for residential customers in Germany (with few exceptions for industrial consumers), the differences in wholesale prices are a good approximation of how the time depending prices for residential customers in Germany would behave. Optimization based on the wholesale market price signal should therefore produce similar results as with time-of-use tariffs for residential customers. However, costs and savings achieved by smart charging algorithms cannot be directly transferred into practice, as they do not consider taxes and levies.

\section{$\mathrm{CO}_{2}$ Emissions}

The emission factor specifies how much greenhouse gases are emitted into the atmosphere generating one $\mathrm{kWh}$ of electric energy. Other greenhouse gases than $\mathrm{CO}_{2}$ are converted into $\mathrm{CO}_{2}$ equivalents. Table 1 also contains the share of total generation $s^{g}$ of generation technology $g$ of all considered technologies $G$. There are gross emission factors that take into account the entire production chain and net emission factors that only consider emissions from the burned fuel. Gross emission factors $f_{g}^{g}\left[g / k W h_{e l}\right]$ also include the emissions from upstream and downstream process chains. We used the mean of the interval given in Wagner et al. (2007) as the emission factor $f^{g}$ for generation technology $g$. For other renewables, pump storage, and other non-renewables no emission factor was given. However, their contributions to the total generation in Germany are very low (see Table 1). For this technologies we assume $f_{g}^{g}$ to be the the average annual emission factor of the same year as in Wagner et al. (2007) being $621 \mathrm{~g} / \mathrm{kWh}$ (2017). The negative

Table $1 \mathrm{CO}_{2}$ gross and net emission factors $\mathrm{f}^{g}$ and generation shares $s^{g}$ of electricity generation technologies in Germany 2017 taken from Wagner et al. (2007), Ensslen et al. (2017), and statista.com (2017)

\begin{tabular}{llll}
\hline Generation & $f_{g}^{g}\left[\mathrm{~g} / \mathrm{kWh} h_{e}\right]$ & $f_{n}^{g}\left[\mathrm{~g} / \mathrm{kWh} h_{e l}\right]$ & $s^{g}[\%]$ \\
\hline Biomass & -200.0 & 0.0 & 7.0 \\
Hydro Power & 25.0 & 0.0 & 3.0 \\
Wind Offshore & 25.0 & 0.0 & 3.0 \\
Wind Onshore & 25.0 & 0.0 & 16.0 \\
Photovoltaics & 75.0 & 0.0 & 7.0 \\
Other Renewables & 621.0 & 0.0 & 0.0 \\
Nuclear Power & 20.0 & 0.0 & 14.0 \\
Lignite & 1025.0 & 1159.7 & 24.0 \\
Hard Coal & 925.0 & 904.8 & 12.0 \\
Natural Gas & 475.0 & 376.8 & 3.0 \\
Pump Storage & 0.0 & 0.0 & 1.0 \\
Other Non-Renewables & 621.0 & 328.1 & 10.0 \\
\hline
\end{tabular}


emission factor of biomass results from fuel savings through co-generation and because the rotting of biomass would produce methane that is more climate-damaging than the $\mathrm{CO}_{2}$ released during combustion (Wagner et al. 2007). For the calculations we used the net emission factor $f_{n}^{g}$ from Ensslen et al. (2017) that only considers the emissions from fuels burned during generation. This is based on the notion that the temporal flexibility only has no immediate effect on the generation structure.

The $\mathrm{CO}_{2}$ emissions $e_{t}$ for every quarter of an hour $t$ are calculated based on the emission factor of the generation technologies and their contribution to electricity generation at that time:

$$
e_{t}=\sum_{G}\left(s_{t}^{g} * f^{g}\right) .
$$

Figure 1 shows the mean emission factor over the course of an average day in 2017. There are low emissions during the day and slight peaks in the morning and evening hours. This is explained by the fact that the feed in on PV replaces conventional generation during noon. In the hours of high load (at noon and in the evening) renewable generation is far from sufficient to satisfy the demand and more conventional power plants feed into the system. Savings potentials through load shifting can be expected mainly through a shift from morning to noon and evening into the night. Th curve looks shows some resemblance to the wholesale electricity prices in Germany. Accordingly, the correlation between the wholesale electricity price and the emission factor is high $\left(R^{2}=0.63\right)$. Even as PV seems to be the main driver of the change in net emission factors, the changes of $\mathrm{CO}_{2}$ emission factors show no clear pattern over the course of a year. However, this is less relevant for optimizing charging as BEV users cannot move their charging over several weeks.

\section{Methodology}

To analyze the potential $\mathrm{CO}_{2}$ savings, we first make assumptions about the charging process of the BEVs. It is determined by the power and energy capacity, the timing, and the temporal flexibility of the BEV user. The charging demand is covered by three different charging algorithms. These algorithms are then compared on the basis of their costs, $\mathrm{CO}_{2}$ savings, and time requirements. We use a discrete model that divides the year 2017 into $\bar{t}=15$ min intervals. As a limiting assumption, we assume that shifting the charging has

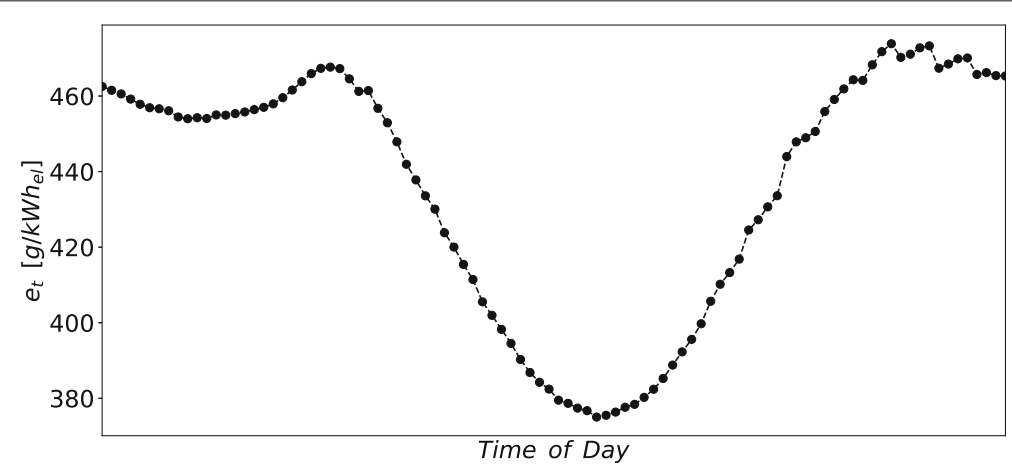

Fig. 1 Mean emission factor in Germany $e_{t}$ over the course of a day 
no influence on the $\mathrm{CO}_{2}$ gross emission factors $e_{t}$ of the German energy system. This seems plausible, as the number of BEVs in Germany is still very low.

\section{Charging demand}

We model a charging demand following the discrete battery model of Petersen et al. (2013). The duration of a discrete time step is called $\bar{t}$. At a end time $t_{e}$ a certain amount of energy $W_{t_{e}}$ must have flown into the BEV. The charging process at charging power $P_{t}$ can be interrupted or reduced in each time step $t$ and is limited upwards by a capacity restriction $\hat{P}$. This describes the maximum charging capacity of the BEV and the charging station. A charging process is described by its starting time $t_{s}$ and its latest possible end $t_{e}$. The difference resembles the temporal charging flexibility $h$ of the BEV user:

$$
h=t_{e}-t_{s}
$$

Note that a charging process can also be completed before reaching $t_{e}$. We call this point in time $t_{e}^{A}$ with charging algorithm $A$ and $h^{A}$ as charging time with algorithm $A$.

\section{Charging algorithms}

We consider three charging algorithms: Immediate charging $A^{i}, \mathrm{CO}_{2}$ emission minimizing charging $A^{e}$ and a cost-optimal algorithm $A^{p}$. The three charging algorithms differ in their optimization goals: Algorithm $A^{i}$ minimizes the time $h$ needed for the charging process under the constraints that the maximum charging capacity $\hat{P}$ is not exceeded by the energy inflow $w_{t}$ in any time step and the BEV is fully loaded at $t_{e}$. Keep in mind that our flexibility contains only a temporal component $h$ and therefore $W_{t_{e}}$ must always be reached:

$$
\begin{array}{ll}
\min _{w_{t}} & h^{i}\left(w_{t}, W_{t_{e}}, \hat{P}\right) \\
\text { s.t. } & w_{t}=\hat{P} * \bar{t} \\
& \sum_{t=t_{s}}^{t_{s}+h} w_{t}=W_{t_{e}} .
\end{array}
$$

Algorithm $A^{e}$ minimizes $\mathrm{CO}_{2}$ emissions $\epsilon_{t_{s}, h}^{A}$ from electricity generation during the charging process stated in $t_{s}$ with charging flexibility $h$. Whereby $\epsilon_{t_{s}, h}^{A}$ is based on the $\mathrm{CO}_{2}$ temporal emission factor $e_{t}$ and the energy demand $w_{t}$ :

$$
\begin{array}{ll}
\min _{w_{t}} & \epsilon_{t_{s}, h}^{A}=\sum_{t=t_{s}}^{t_{s}+h}\left(w_{t} * e_{t}\right) \\
\text { s.t. } & w_{t} \leq \hat{P} * \bar{t} \\
& \sum_{t=t_{s}}^{t_{s}+h} w_{t}=W_{t_{e}} .
\end{array}
$$

Similarly, algorithm $A^{p}$ minimizes the cost of electricity purchases $\gamma_{t_{s}, h}^{A}$ during the charging process

$$
\min _{w_{t}} \gamma_{t_{s}, h}^{A}=\sum_{t=t_{s}}^{t_{s}+h}\left(w_{t} * c_{t}\right) \text {, }
$$


where the $c_{t}$ is the wholesale electricity price at $t$ and the constraints are the same as in Eq. (4).

\section{Evaluation}

To our knowledge, there are no open data sets that represent the charging needs and flexibility of real BEV users. However, there are various works on synthetic driving profiles, from which the charging capacity and the flexibility of different BEV user types can be simulated (e.g., in Schuller et al. (2015)). These could be used to determine the potential for $\mathrm{CO}_{2}$ savings of different user types. Nevertheless, it is questionable whether the synthetic data really allow generalizing statements. In addition, our goal is to estimate the potential for individual charging situations in order to provide feedback to the user and not to take an overall view. We therefore decided to base our analysis on synthetic exemplifying charging situations.

For this purpose we base on the values of Schuller et al. (2015) and assume a maximum loading capacity of $\hat{P}=10 \mathrm{~kW}$ and a loading requirement of $W_{t e}=30 \mathrm{kWh}$. We simulate 35,040 charging processes for all quarter-hours in 2017. Each charging process is conducted based on the three charging algorithms and five flexibility classes $h$. The flexibility classes represent different temporal flexibility of the BEV users: The immediate charging $(h=3: 00 \mathrm{~h})$ is used as a benchmark $\left(A^{i}\right)$ and a temporal flexibility of up to $h=8: 00 \mathrm{~h}$ (e.g., charging overnight) are investigated.

\section{Results}

With the benchmark algorithm $A^{i}$ (i.e., immediate charging during the next $3 \mathrm{~h}$ ), the average $\mathrm{CO}_{2}$ emissions $E^{i}$ for charging are 20,132.6 g. The cost $C^{i}$ are unrealistically low at 1.03 Euro. This is due to the fact that only the wholesale market prices without taxes and levies are used. Average relative differences of the other two algorithms towards the benchmark algorithm $A^{i}$ are displayed in Table 2 . The relative differences in avoided emissions and reduced costs by algorithm $a$ for starting time $t_{s}$ and charging flexibility $h$ are calculated as

$$
\delta E_{t_{s}, h}^{a}=\frac{\epsilon_{t_{s}, h}^{a}-\epsilon_{t_{s}}^{A^{i}}}{\epsilon_{t_{s}}^{A^{i}}} .
$$

In the same way the cost differences $\delta C_{t_{s}, h}^{a}$ are calculated, as is the extension of the loading time $\delta T_{t_{s}, h}^{a}$. Consider that also for the algorithms $A^{e}$ and $A^{p}$ the charging duration $h_{t_{s}, h}^{a}$ can be below the maximum charging flexibility $h$.

By extending the charging time by $33 \%$ to $4: 00 \mathrm{~h}$, the algorithm $A^{e}$ can on average only avoid $1.54 \%$ of $\mathrm{CO}_{2}$ emissions. By increasing the charging time to $8: 00 \mathrm{~h}$, on average

Table 2 Mean relative $\mathrm{CO}_{2}(\delta E)$ and cost differences $(\delta C)$ for charging algorithm a and different temporal flexibility $h$ compared to immediate charging $A^{i}$

\begin{tabular}{llllllll}
\hline & \multicolumn{3}{c}{$A^{e}-$ minimal emissions } & & \multicolumn{3}{c}{$A^{P}$ minimal costs } \\
\cline { 2 - 3 }$h$ (increase) & $\delta E[\%]$ & $\delta C[\%]$ & $\delta T[\%]$ & & $\delta E[\%]$ & $\delta C[\%]$ & $\delta T[\%]$ \\
\hline $4: 00 \mathrm{~h} \mathrm{(33 \% )}$ & -1.54 & -2.94 & 22.80 & & -0.61 & -4.89 & 23.33 \\
5:00 h (67\%) & -2.92 & -5.68 & 44.23 & & -1.29 & -10.32 & 46.23 \\
6:00 h (100\%) & -4.17 & -7.75 & 64.80 & & -1.88 & -15.16 & 68.22 \\
8:00 h (167\%) & -6.40 & -10.10 & 104.61 & & -2.76 & -21.02 & 110.87 \\
\hline
\end{tabular}


emission reductions of $6.40 \%$ are achieved. At the same time, minimizing $\mathrm{CO}_{2}$ emissions reduces the charging costs on average. On average, the avoided $\mathrm{CO}_{2}$ emissions and cost reductions are in the same direction, no matter whether $A^{e}$ or $A^{p}$ are applied. For both algorithms, the BEVs are on average fully charged well ahead of the flexibility horizon.

Figure 2 shows how the potential for $\mathrm{CO}_{2}$ savings are distributed over an average day. If the charging process starts at noon or midnight hardly any $\mathrm{CO}_{2}$ savings are possible, regardless of the temporal flexibility provided. This would of course change if more temporal flexibility than 8:00 $\mathrm{h}$ was provided. $\mathrm{CO}_{2}$ saving potentials are especially large for postponed charging starting in the early morning or in the evening.

\section{Discussion}

The results show that there are different saving potentials for $\mathrm{CO}_{2}$ emissions using the temporal flexibility of BEV charging. However, if charging loads are shifted to a large extent, this would affect the dispatch of the generation units, which could nullify the effect again. Based on this findings, the BEV user can obtain direct feedback on the possible $\mathrm{CO}_{2}$ savings given their charging requirements, starting time and temporal charging flexibility. The magnitude of the saving potentials of postponed charging is approximately on the same level (5\%) as energy savings obtained by feedback and intervention studies for household energy consumption (Abrahamse et al. 2005).

The saving potentials strongly depend on the starting time of the charging process and the temporal flexibility of the BEV user. Especially if flexibility is provided in the late evening or at in the early morning hours, this can avoid $\mathrm{CO}_{2}$ emissions. This is because the peaks in the $\mathrm{CO}_{2}$ emission factor can be avoided (see Fig. 1). A $\mathrm{CO}_{2}$-conscious BEV user should therefore provide flexibility during the day to obtain the highest $\mathrm{CO}_{2}$ savings. However, this is also the time when many car and BEV users use their vehicles to get to work (Schuller et al. 2015). Such users cannot reach their full $\mathrm{CO}_{2}$ saving potential. In order for them to benefit from PV feed-in, charging options must be available at the workplace.

It should be noted that the considered optimization objectives set identical incentive signals for all BEVs using such a system which would lead to the correlating charging patterns. This could affect the generation dispatch or oppose other applications of smart charging systems (e.g., the avoidance of congestion in the grid). Therefore, feedback on $\mathrm{CO}_{2}$ savings should be seen as a feature of smart charging systems that can possibly nudge

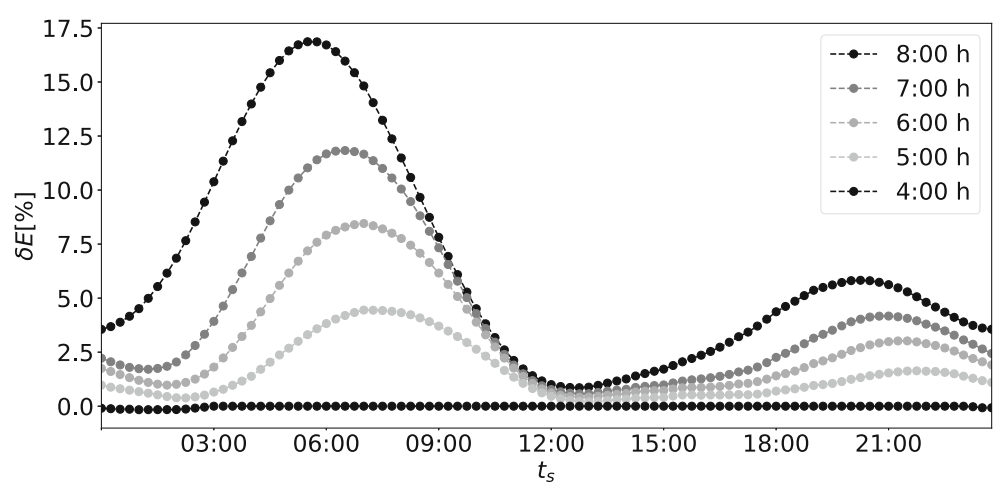

Fig. 2 Relative $\mathrm{CO}_{2}$ reduction $\delta E$ for different temporal flexibility $h$ and starting times $t_{s}$ 
users to provide more flexibility. However, the flexibility should be used also for other purposes than only optimizing $\mathrm{CO}_{2}$ emissions.

We have also performed the calculations with the gross emission factors from Table 1. The average daily savings potential is of a comparable magnitude. However, the hours with the greatest savings potential are postponed to the night hours.

\section{Conclusion}

This paper suggests feedback on $\mathrm{CO}_{2}$ saving potentials as a possible feedback nudge for providing temporal flexibility at BEV charging. An analysis based on market and generation data from Germany shows that postponing BEV charging has the potential to avoid $\mathrm{CO}_{2}$ emissions compared to immediate charging. The results could be implemented as feedback nudge to encourage BEV users to provide more temporal charging flexibility. Non-energy professionals may have problems understanding $\mathrm{CO}_{2}$ savings. It might therefore be helpful to provide the BEV user with mappings (see Münscher et al. (2016)). This could be a comparison with the driving distance of an internal combustion engine in terms of $\mathrm{CO}_{2}$ emissions saved or a conversion in a volume unit. Whether the effect of such mapping can further enhance any effect of feedback must be further investigated by further experiments.

As the saving potentials are only in the low percentage rates, the question arises as to whether they are still sufficient as an incentive or nudge for BEV users to provide more temporal flexibility. This question will be further evaluated in user surveys and experiments. Since the cost-optimizing charging algorithm has similar $\mathrm{CO}_{2}$ saving potentials effects, the feedback on $\mathrm{CO}_{2}$ savings can also be combined with financial feedback without contradicting the goal of saving $\mathrm{CO}_{2}$. However, this only applies if the prices for BEV users are aliened with the prices on the wholesale electricity market.

The current approach is based on the assumption that the shifted charging does not effect the generation dispatch and the smart charging system has perfect foresight. It can therefore only offer the users feedback based on historical saving potentials. An actual smart charging algorithm would need operate on a short-term forecast for the $\mathrm{CO}_{2}$ emission factors. For this, a short-term forecast for $\mathrm{CO}_{2}$ emission factors during the next few hours is required. Since the pattern of $\mathrm{CO}_{2}$ emission factors shows a high similarity to wholesale prices, this forecast could base on findings on short-term electricity price forecasting. The optimization further has to deal with the uncertainty of these forecasts in order to achieve the best possible charging pattern. The results presented here can serve as a benchmark in such a development.

In the following study we will use the results to conduct the final step of the digital nudging framework (Weinmann et al. 2016). Therefore we develop an experimental setup to test in what way feedback on $\mathrm{CO}_{2}$ emissions can nudge $\mathrm{BEV}$ users to provide temporal flexibility.

Abbreviations

BEV: Battery Electric Vehicle; PV: Photovoltaics

\section{Acknowledgements}

The authors thank Nicole Ludwig, Uli Hörnig, and Frederik Klatt for fruit-full discussions, and remarks. Last, we thank reviewers for their constructive criticism and valuable comments.

\section{Funding}

The authors want to thank the Germany Federal Ministry for Economic Affairs and Energy for the funding and support. Publication costs for this article were sponsored by the Smart Energy Showcases - Digital Agenda for the Energy Transition (SINTEG) programme. 
Availability of data and materials

The results were obtained based on the datasets available at SMARD and the assumptions described in the paper.

\section{About this Supplement}

This article has been published as part of Energy Informatics Volume 1 Supplement 1, 2018: Proceedings of the 7th DACH+ Conference on Energy Informatics. The full contents of the supplement are available online at https:// energyinformatics.springeropen.com/articles/supplements/volume-1-supplement-1.

\section{Authors' contributions}

$\mathrm{JH}$ raised and developed the overall idea of the work, carried out the analysis, and drafted the manuscript. CW contributed in the overall idea of the work, provided research direction, supervision, and funding. Both authors read and approved the final manuscript.

\section{Competing interests}

The authors declare that they have no competing interests.

\section{Publisher's Note}

Springer Nature remains neutral with regard to jurisdictional claims in published maps and institutional affiliations.

\section{Author details}

${ }^{1}$ FZI Research Center for Information Technology, Haid-und-Neu-Str. 10-14, 76131 Karlsruhe, Germany. ${ }^{2}$ Karlsruhe Institute of Technology, Fritz-Erler-Str. 23, 76131 Karlsruhe, Germany.

\section{Published: 10 October 2018}

\section{References}

Abrahamse W, Steg L, Vlek C, Rothengatter T (2005) A review of intervention studies aimed at household energy conservation. J Environ Psychol 25(3):273-291

Asensio OI, Delmas MA (2016) The dynamics of behavior change: Evidence from energy conservation. J Econ Behav Organ 126:196-212

Clement-Nyns K, Haesen E, Driesen J (2010) The impact of charging plug-in hybrid electric vehicles on a residential distribution grid. IEEE Trans Power Syst 25(1):371-380

Ensslen A, Schücking M, Jochem P, Steffens H, Fichtner W, Wollersheim O, Stella K (2017) Empirical carbon dioxide emissions of electric vehicles in a french-german commuter fleet test. J Clean Prod 142:263-278

Entwicklung des CO2-Emissionsfaktors Für Den Strommix in Deutschland in Den Jahren 1990 Bis 2016 (2017). https://de. statista.com/statistik/daten/studie/38897/umfrage/co2-emissionsfaktor-fuer-den-strommix-in-deutschland-seit1990/. Accessed 3 Aug 2018

Gottwalt S, Schuller A, Flath C, Schmeck H, Weinhardt C (2013) Assessing load flexibility in smart grids: Electric vehicles for renewable energy integration. In: Power and Energy Society General Meeting (PES), 2013 IEEE. IEEE, Vancouver. pp 1-5. https://ieeexplore.ieee.org/document/6672854/

Grønhøj A, Thøgersen J (2011) Feedback on household electricity consumption: learning and social influence processes. Int J Consum Stud 35(2):138-145

Ludwig N, Waczowicz S, Mikut R, Hagenmeyer V (2017) Mining flexibility patterns in energy time series from industrial processes. In: Proceedings. 27. Workshop Computational Intelligence, Dortmund, 23.-24. November 2017. KIT Scientific Publishing, Karlsruhe. p 13. https://publikationen.bibliothek.kit.edu/1000076645

Magana VC, Munoz-Organero M (2011) Artemisa: An eco-driving assistant for android os. In: Consumer Electronics-Berlin (ICCE-Berlin), 2011 IEEE International Conference On. IEEE, Berlin. pp 211-215. https://e-archivo.uc3m.es/handle/ 10016/13084

McCright AM, Dunlap RE (2011) The politicization of climate change and polarization in the american public's views of global warming, 2001-2010. Sociol Q 52(2):155-194

Münscher R, Vetter M, Scheuerle T (2016) A review and taxonomy of choice architecture techniques. J Behav Decis Mak 29(5):511-524

Petersen MK, Edlund K, Hansen LH, Bendtsen J, Stoustrup J (2013) A taxonomy for modeling flexibility and a computationally efficient algorithm for dispatch in smart grids. In: American Control Conference (ACC), 2013. IEEE, Washington. pp 1150-1156. https://ieeexplore.ieee.org/document/6579991/

Salah F, Flath CM (2016) Deadline differentiated pricing in practice: marketing ev charging in car parks. Comput Sci-Res Dev 31(1-2):33-40

Santos G (2017) Road transport and CO2 emissions: What are the challenges?. Transp Policy 59:71-74

Schuller A, Flath CM, Gottwalt S (2015) Quantifying load flexibility of electric vehicles for renewable energy integration. Appl Energy 151:335-344

Schultz PW, Nolan JM, Cialdini RB, Goldstein NJ, Griskevicius V (2007) The constructive, destructive, and reconstructive power of social norms. Psychol Sci 18(5):429-434

SMARD Strommarktdaten. https://www.smard.de/home. Accessed 3 Aug 2018

Sortomme E, El-Sharkawi MA (2011) Optimal charging strategies for unidirectional vehicle-to-grid. IEEE Trans Smart Grid 2(1):131-138

Thaler RH, Sunstein CR (2008) Nudge: Improving decisions about health, wealth, and happiness. Yale University Press, New Haven \& London

Tversky A, Kahneman D (1974) Judgment under uncertainty: Heuristics and biases. Science 185(4157):1124-113 
Wagner H-J, M Koch JB, Böckmann TG, Feck N, Kruse P (2007) CO2-Emissionen der Stromerzeugung - Ein ganzheitlicher Vergleich verschiedener Techniken. In: VDI (ed). BWK Das Energie-Fachmagazin. Springer, Düsseldorf, Germany Vol. 10. pp 44-59

Weinmann M, Schneider C, vom Brocke J (2016) Digital nudging. Bus Inf Syst Eng 58(6):433-436

Will C, Schuller A (2016) Understanding user acceptance factors of electric vehicle smart charging. Transp Res C: Emerg Technol 71:198-214

Submit your manuscript to a SpringerOpen ${ }^{\circ}$ journal and benefit from:

- Convenient online submission

- Rigorous peer review

- Immediate publication on acceptance

- Open access: articles freely available online

- High visibility within the field

- Retaining the copyright to your article

Submit your next manuscript at $\$$ springeropen.com 